\title{
Iniciativas de Ciência de Dados e Analytics da Universidade de Pernambuco
}

\author{
Uma edição especial voltada para os trabalhos acadêmicos desenvolvidos na UPE
}

\author{
Alexandre Magno Andrade Maciel 1 (Dorcid.org/0000-0003-4348-9291 \\ Rodrigo Lins Rodrigues ${ }^{2}$ (Dorcid.org/0000-0002-3598-5204 \\ Mailson Melo dos Santos Filho 3 (Borcid.org/0000-0002-1711-5301
}

\footnotetext{
${ }^{1}$ Escola Politécnica de Pernambuco, Universidade de Pernambuco, Recife, Brasil,

2 Departamento de Educação, Universidade Federal Rural Pernambuco, Recife, Pernambuco, Brasil,

${ }^{3}$ Fábrica de Negócios - Analytics \& Data Mining, Recife, Pernambuco, Brasil.

E-mail do autor principal: amam@ecomp.poli.br
}

Em fevereiro de 2010 a revista The Economist publicou uma edição especial intitulada Data, Data Everywhere na qual foi realizado uma profunda análise do cenário mundial sobre o que eles chamaram de uma quantidade inimaginável de informação digital que está ficando cada vez mais vasta, mais rapidamente. Naquele momento, eles avaliaram que esse grande volume de dados poderia proporcionar grandes avanços para a economia e para a sociedade tais como: tendências de mercado, prevenção de doenças, combate à criminalidade entre outros. Por outro lado, estas benesses viriam acompanhadas de uma série de novos problemas tais como: dificuldades de armazenamento de dados oriundos de diversas fontes (web, sensores, dispositivos móveis), segurança dos dados e proteção da privacidade dos usuários [1].

No Brasil, este cenário tem demorado alguns anos para ser replicado, como mostra a pesquisa da Computer World que mostrou que o mercado nacional representou em $201646,8 \%$ do mercado na América Latina, gerando receita de US\$1,16 bilhão. Esta é uma fatia ínfima do mercado visto que a América Latina como um todo corresponde a apenas por 5,1\% do mercado global [2]. Este crescente interesse do mercado tem demandado também a formação de um conjunto de novos profissionais especializados em Ciência de Dados e Analytics. Cientista de Dados, Arquiteto de Dados, Engenheiro de Dados, Analista de Negócios e Desenvolvedor de Visualização de Dados são alguns dos cargos que tem ganhado cada vez mais relevância dentro das organizações [3].

Diante deste contexto global, em maio de 2016 foi proposto o Curso de Especialização em Ciência de Dados e Analytics na Escola Politécnica (POLI) da Universidade de Pernambuco (UPE). A proposta, essencialmente inovadora, foi construída a partir de uma colaboração entre as quatro universidades públicas de Pernambuco: UPE, Universidade Federal Rural de Pernambuco (UFRPE), a Universidade Federal de Pernambuco (UFPE), a Universidade de Vale do São Francisco (UNIVASF) e com a participação da empresa Fábrica de Negócios - Analytics \& Data Mining. O curso está fundamentado num tripé de conhecimento baseado em disciplinas da área de inteligência computacional, de infraestrutura e banco de dados e de negócios e tem como público alvo profissionais da área de computação, engenharias, estatística e administração. O curso encontra-se na sua terceira turma e esta edição especial da Revista de Engenharia e Pesquisa Aplicada (REPA) é aberta com dez artigos que representam o trabalho de conclusão de curso referente a turma de 2016.

Outra ação acadêmica importante da Universidade de Pernambuco que vem ganhando atenção do mercado e do governo local é uma iniciativa chamada Sala de Aula Aberta. Esta ação iniciou no segundo semestre de 2016 com as disciplinas de inteligência artificial e mineração de dados do Curso de Graduação e de Mestrado em Engenharia da Computação, e tem como objetivo, aplicar uma metodologia de Aprendizagem Baseada em Problemas, trazendo para sala de aula 
demandas reais de problemas complexos de empresas e das unidades gestoras do governo do estado. Durante a disciplina os alunos se debruçam sobre o entendimento das problemáticas, análise e pré-processamento dos dados e, a partir do estudo das diversas abordagens de inteligência artificial, propõem soluções, em nível de prova de conceito, que são entregues aos demandantes e tem potencial para tornar-se soluções tecnológicas de apoio à decisão. Os últimos oito artigos desta edição apresentam os resultados obtidos a partir do Sala de Aula Aberta.

É notória a importância que a área de Ciência de Dados e Analytics vem ganhando no Recife, e, isto se comprova na busca por estas duas ações da UPE, além de outras ações que vêm surgindo na cidade como novos cursos de extensão e especialização, hackthons promovidos a partir de análise de dados de diversas empresas, bem como o surgimento de diversas startups focadas nesta área. Isto posto, é com enorme satisfação que entregamos esta edição especial da REPA, resultado de um esforço visionário da POLI/UPE, como apoio dos diversos parceiros acadêmicos e da indústria, para nos colocarmos na vanguarda da formação tecnológica do estado, e consolidarmos um grupo de professores/pesquisadores a atuarem de maneira decisiva no fortalecimento do ecossistema de inovação do país.

\section{Referências}

[1] Data, data everywehre. The Economist, 25 Feb.2010. Disponível em: < https://www.economist.com/special-report/2010/02/25/data-data-everywhere>

[2] Mercado brasileiro de big data e analytic fatura US\$1,16 BI e já representa 50\% AL. Computerworld, 21 mar. 2017. Disponível em: < http://computerworld.com.br/2017/03/21/mercado-brasileiro-de-big-data-e-analytics-fatura-us116-bi-e-ja-representa-quase-50-da-al/>

[3] 10 Carreiras em Big Data e Data Science. Data Science Academy, 25 out. 2016. Disponível em: <http://datascienceacademy.com.br/blog/10-carreiras-em-big-data-e-data-science/> 